\title{
HABILIDADES SOCIAIS DE AMIZADE E CIVILIDADE NO CONTEXTO ESCOLAR
}

\author{
Thaisa da Silva Fonseca \\ Universidade Estadual do Piauí (UESPI) \\ Cássia Maria Lopes Dias Medeiros \\ Psicóloga Escolar \\ Ana Célia Sousa Cavalcante \\ Universidade Estadual do Piauí (UESPI)
}

\begin{abstract}
Resumo
Este trabalho objetiva relatar a experiência das atividades desenvolvidas no projeto Habilidades Sociais da Criança durante o segundo semestre letivo de 2015 em uma escola da rede privada de ensino do município de Teresina. A temática teve como justificativa a promoção de atividades que facilitassem o desenvolvimento das habilidades de amizade e de civilidade junto a alunos do primeiro ano do Ensino Fundamental. Nessa perspectiva, foram promovidas vivências grupais considerando a faixa-etária dos participantes do projeto em foco e utilizaram-se recursos metodológicos lúdicos. Com a realização dos encontros, percebeu-se como significativo o desenvolvimento de habilidades sociais no espaço escolar, em contextos grupais, como prevenção de conflitos e exercício de convivência coletiva.

Palavras-chave: psicologia escolar; atuação profissional; habilidades sociais.
\end{abstract}

\section{SOCIAL SKILLS OF FRIENDSHIP AND CIVILITY IN THE SCHOOL CONTEXT}

\begin{abstract}
This work aims to relate experiences obtained through a Children's Social Skills project developed in the second half-2015 at a private school in Teresina-PI. The thematic is justified by promoting activities that involved civility and friendship skills among students from first year of elementary school. In this context, it was developed experiences on group activities, based on participant's age and using a playful methodology. With the meetings, meaningfully social skills in groups' contexts at the school environment emerged, as a way of prevention of conflicts and of exercising a collective social interaction.
\end{abstract}

Keywords: school psychology; professional performance; social skills.

\section{CAPACIDADES SOCIALES DE AMISTAD Y CIVILIDAD EN UN CONTEXTO EDUCATIVO}

\begin{abstract}
Resumen
Este trabajo tiene como meta la experiencia de las actividades desarrolladas en el diseño Habilidades Sociales de niños durante el segundo semestre del año 2015 en una escuela de la red privada de enseñanza del municipio de Teresina. La temática tuve como justificación la promoción de actividades para facilitar el desarrollo de las capacidades de amistad y civilidad con los alumnos del primer año de la enseñanza fundamental. Así eran promovidas experiencias en grupos en consideración con la edad de los participantes del proyecto usando medios de juguetón. Con el logro de los encuentros, fue sentido como tenia significado el desarrollo de las capacidades sociales en la escuela, en grupos utilizando la prevención de conflictos y ejercicio de convivencia en general.
\end{abstract}

Palabras clave: psicología en la escuela; actuación profesional; capacidades sociales. 


\section{INTRODUÇÃO}

A infância tem sido apontada como período crítico para o desenvolvimento de habilidades sociais (Bandeira et al., 2006). A preocupação de pais e profissionais de saúde e educação com a competência social da criança pode ser vista tanto na perspectiva da promoção de qualidade de vida como da prevenção de problemas na infância e adolescência. O investimento da escola na promoção de habilidades sociais justifica-se na função social da escola, na relação habilidades sociais e desempenho acadêmico, e nas políticas inclusivas (Del Prette \& Del Prette, 2005).

Na sociedade atual, a criança precisa desenvolver um repertório cada vez mais elaborado de habilidades sociais. Os termos desempenho social, habilidades sociais e competência social inter-relacionam-se. O desempenho social refere-se à emissão de um comportamento, de forma individualizada ou sequencial, em uma situação social. Habilidades sociais referem-se às diferentes classes de comportamentos sociais do repertório de um indivíduo, que contribuem para a competência social, favorecendo um relacionamento saudável e produtivo com as demais pessoas. A competência social diz respeito à capacidade de articular pensamentos, sentimentos e ações em acordo com os fatores da situação, da pessoa e da cultura, acarretando consequências positivas para o indivíduo e o relacionamento interpessoal (Del Prette \& Del Prette, 2001; 2005).

Considerando a importância das habilidades sociais na vida diária do ser humano, é necessário que o mesmo aprenda sobre seu comportamento social e dos demais e, principalmente, saiba que esse comportamento pode ser modificado e conheça algumas formas para fazê-lo (Caballo, 2003). As habilidades sociais são divididas em classes, sendo sete consideradas prioritárias no desenvolvimento interpessoal da criança: autocontrole e expressividade emocional; civilidade; empatia; assertividade; fazer amizades; solução de problemas interpessoais; e habilidades sociais acadêmicas. Essas classes são interdependentes e complementares, de modo a contemplarem as principais demandas interpessoais (Del Prette \& Del Prette, 2005).

Enfocar-se-á, a seguir, nas habilidades de fazer amizades e de civilidade. Del Prette e Del Prette (2005) discorrem que a habilidade de fazer amizades envolve fazer e responder perguntas, oferecer e aproveitar informações livres, sugerir atividades, cumprimentar, apresentar-se, elogiar e aceitar elogios, iniciar e manter conversação, dentre outras subclasses. A habilidade de civilidade, por sua vez, envolve a expressão comportamental de regras mínimas de relacionamento aceitas em determinada cultura, tendo em vista que o conhecimento das regras sociais de um grupo é fundamental para a inserção e participação efetivas nele. Essa habilidade inclui, dentre outras subclasses, cumprimentar pessoas, aguardar a vez para falar, fazer e aceitar elogios, seguir regras ou instruções, fazer e responder perguntas. 
Com base no exposto, o psicólogo, enquanto profissional também atuante no ambiente educacional, pode colaborar com a promoção de trabalhos referentes ao desenvolvimento de habilidades sociais nesse contexto, uma vez que Barbieri et al. (2007) afirmam que o psicólogo escolar desenvolve ações direcionadas a alunos, professores e funcionários, agindo tanto na frente preventiva como na frente que demanda mudanças, de modo a contribuir para o desenvolvimento cognitivo, humano e social de toda a comunidade escolar.

Esse modelo de atuação justifica-se na medida em que se compreende que o psicólogo precisa estar inserido como membro efetivo da instituição escolar e não apenas como um especialista que presta consultoria em momentos pontuais. Entende-se, assim, como necessária uma dimensão de prevenção e promoção na prática desse profissional (Almeida \& Marinho-Araújo, 2010).

Percebe-se que a temática habilidades sociais, relevante campo de estudo, apresenta-se como foco de intervenção do psicólogo no espaço escolar. Considerando-se as características do desenvolvimento infantil, a promoção de um trabalho com o intuito de desenvolver habilidades sociais, utilizando-se de contexto grupal e do conhecimento teórico e metodológico da Psicologia na interface com a Educação, é recomendável e significativo.

No contexto escolar, o psicólogo desenvolve a sua atuação não somente mediante demandas já existentes. Nesse sentido, o Projeto Habilidades Sociais da Criança foi implantado pelo Serviço de Psicologia de uma escola da rede privada de ensino do município de Teresina com o objetivo de desenvolver habilidades sociais junto ao aluno, no contexto interdisciplinar, a fim de ampliar a sua competência social, visando um bom funcionamento adaptativo.

No segundo semestre letivo de 2015, o referido projeto contou com a participação de uma estagiária vinculada ao curso de Psicologia da Universidade Estadual do Piauí (UESPI) e promoveram-se atividades com o intuito de desenvolver as habilidades sociais de amizade e de civilidade. Dessa forma, o presente artigo objetiva relatar a experiência das atividades desenvolvidas no Projeto Habilidades Sociais da Criança nesse período.

\section{PREPARANDO O DESENVOLVIMENTO DAS ATIVIDADES}

O Projeto Habilidades Sociais da Criança, anteriormente implantado pelo Serviço de Psicologia do campo de estágio onde esta experiência foi vivenciada, contemplou alunos do primeiro ano do Ensino Fundamental, turnos manhã e tarde. Cada turma possuía, em média, vinte a trinta alunos. Os participantes, dos sexos masculino e feminino, possuíam de seis a sete anos de idade.

No segundo semestre letivo de 2015, as atividades do projeto foram desenvolvidas a partir das habilidades sociais amizade e civilidade, que ganharam significado através da realização de atividades de leituras, vivências 
grupais, expressões por meio das artes visuais e plásticas, expressão musical e corporal, dentre outras.

Em momento anterior ao início das atividades, analisaram-se com base no calendário escolar as datas indicadas como viáveis para a concretização dos encontros envolvendo as habilidades sociais mencionadas. A estagiária, junto ao Serviço de Psicologia Escolar, combinou com as professoras dos alunos públicoalvo do projeto o melhor horário para a sua realização, de modo a não interferir nas atividades cotidianas.

A proposta de trabalho foi divulgada em sala de aula e os alunos convidados a participarem dos encontros. A psicóloga, supervisora de campo, participou de todos os momentos, desde o planejamento até a realização e avaliação das intervenções realizadas. A construção, acompanhamento e avaliação da proposta de intervenção foram supervisionados pela professora da disciplina.

Seis turmas participaram das intervenções e foram realizados dois encontros em cada turma: o primeiro focalizando a habilidade de amizade e o segundo, a habilidade de civilidade. Cada encontro teve duração aproximada de 40 minutos, tempo considerado suficiente para a execução das atividades planejadas. Os locais de realização dos encontros foram diferentes: o primeiro ocorreu no salão de acolhimento da escola e o segundo, na sala de informática. Isto estava relacionado às necessidades específicas da metodologia de cada encontro e de seu respectivo tema.

As estratégias utilizadas para realização dos encontros grupais foram diversificadas - vídeo, música, coreografia, roda de conversa, história infantil, estímulos sonoros e visuais - de modo a contemplar as especificidades da faixaetária do público-alvo do projeto, optando-se, portanto, pelos recursos lúdicos e vivências grupais com dinâmicas relacionadas às temáticas. Os materiais utilizados nos encontros foram produzidos pela estagiária, sob orientação da supervisora de campo e da professora da disciplina.

Os encontros realizados para trabalhar a habilidade social de amizade ocorreram no mês de setembro de 2015. Inicialmente, os alunos foram direcionados ao salão de acolhimento: primeiro a psicóloga fez a apresentação da estagiária aos alunos e, logo após, foi apresentado o tema do encontro: amizade.

Uma adaptação da atividade "Gostando dos Colegas" (Del Prette \& Del Prette, 2005) foi realizada. Dessa forma, foi utilizado um painel com imagens de pessoas em situações diferentes com balões de falas, e cinco cartões com as frases: "fazer alguma coisa por alguém que gostamos"; "dar opinião sincera e honesta para alguém"; "compartilhar do sucesso ou alegria de alguém"; "incentivar a pessoa que gostamos"; e "dizer para uma pessoa que gostamos dela". Perguntou-se, então, quem gostaria de associar a frase com a imagem correspondente. 
O vídeo intitulado "Cascão \& Cebolinha em Amizade" (Youtube, 2009) foi exibido, e, posteriormente, para promover uma reflexão em torno da vivência, ocorreu uma roda de conversa versando sobre o conteúdo do vídeo exposto, amizade, e sobre como demonstrar que gostamos de alguém.

Na sequência, ocorreu a apresentação do vídeo musical "Valeu, amigo" (Youtube, 2014). Um modelo de coreografia para o refrão da música foi criado e demonstrado pelas facilitadoras e, em seguida, todos cantaram e dançaram juntos. A letra da referida música foi entregue impressa para que os alunos pudessem levá-la para casa com o intuito de as crianças também poderem cantá-la posteriormente.

Os encontros realizados para trabalhar habilidade social de civilidade ocorreram na primeira semana de novembro. No decorrer do mês de outubro, as atividades desenvolvidas na escola estiveram relacionadas à data comemorativa do dia das crianças. Dessa forma, considerou-se relevante que as vivências versassem sobre os direitos e deveres da criança e do adolescente.

Primeiramente, solicitou-se que as crianças sentassem em círculo, disposição adequada para o início de uma roda de conversa. As facilitadoras apresentaram a temática do encontro e iniciou-se perguntando quem conhecia o Estatuto da Criança e do Adolescente, mais conhecido como ECA. Em seguida, explicou-se que o ECA é constituído por um conjunto de leis que protegem as crianças e os adolescentes, informando os seus direitos e deveres. Logo após, mostrou-se um livro do ECA e uma história em formato infantil intitulada "A Turma da Mônica em: O Estatuto da Criança e do Adolescente" (Sousa, 2006). Um material preparado com o recorte dessa história infantil foi exibido em projetor e apresentado às crianças por uma das facilitadoras. À medida que a história era contada, indagações eram feitas tanto pelas facilitadoras como pelas próprias crianças.

Logo após, os participantes foram solicitados, de acordo com o que haviam aprendido com o ECA, a relatar um direito ou dever da criança. Em seguida, distribuíram-se para cada criança duas placas em formato de círculo, nas cores verde e vermelho. Explicou-se para as crianças que a facilitadora iria ler frases com situações cotidianas que estavam relacionadas ao que havia sido discutido no decorrer do encontro e que, após a leitura, o comando seria levantar a placa verde se eles concordassem com a frase ou levantar a placa vermelha se eles discordassem da frase. A seguir, deveriam direcionar as placas para a posição original, de modo que as facilitadoras pudessem apresentar a resposta esperada bem como discutir eventuais indagações.

As frases contidas nos cartões eram: "a criança obedece a seus pais, familiares e professores"; "a criança ajuda sua mãe, arrumando sua cama e seu quarto"; "os pais obrigam a criança a pedir dinheiro no semáforo"; "a criança respeita e é respeitada pelos seus colegas"; "a criança mantém sua escola limpa"; "um adulto machuca uma criança, provocando ferimentos"; "a criança 
não foi para escola hoje, pois estava doente, mas vai todos os outros dias"; "a criança não pode brincar em momento algum"; "a criança está com fome, não tem a comida que ela quer, mas seus pais lhe dão muitas outras 'coisas' para ela comer", dentre outras. Ao final, foi exibido um vídeo musical "Direito da Criança", a fim de discuti-lo e promover reflexões em torno da temática.

\section{RESULTADOS E DISCUSSÃO}

$\mathrm{Na}$ intervenção com o tema amizade, primeiro encontro que contou com a participação da estagiária, as crianças mostraram-se participativas desde o momento inicial de apresentação da estagiária e das crianças. Nesse momento, as subclasses iniciar e manter conversação, cumprimentar e apresentar-se já começaram a ser trabalhadas.

Com a atividade "Gostando dos Colegas" (adaptada de Del Prette \& Del Prette, 2005), ao ser perguntado quem gostaria de associar as imagens e suas respectivas frases, várias crianças prontificaram-se em participar. Dessa forma, cada associação foi realizada por um aluno, os quais fizeram a associação esperada e também comentaram, com contribuições do grupo, sobre a situação cotidiana retratada nas imagens.

A imagem que representava a situação "compartilhar do sucesso ou alegria de alguém" era de um menino sorrindo e falando para dois colegas "fiquei feliz porque vocês tiraram boas notas". A criança responsável pela associação dessa imagem com sua respectiva frase comentou: "Eu também fico feliz quando minha amiga tira boas notas, quando ela ganha presentes...". Percebeu-se, assim, uma generalização do que estava sendo exposto a outras situações cotidianas semelhantes.

Nessa atividade, que contou com a participação ativa não apenas da criança responsável pela associação da imagem com a frase, como também do grupo, foi possível não somente trabalhar a temática amizade a nível grupal como também envolver as subclasses de oferecer e aproveitar informações livres, fazer e responder perguntas, e elogiar e aceitar elogios.

Com a discussão do vídeo "Cascão \& Cebolinha em Amizade" (Youtube, 2009), as crianças expuseram que gostaram do vídeo e falaram frases que representavam a amizade e que se relacionavam ao que foi vivenciado e apresentado no vídeo, como exemplificado com essas frases de duas crianças: "Amizade é carinho, é ajudar o amigo quando ele precisa"; "Amizade são abraços".

Com a apresentação do vídeo musical "Valeu, amigo" (Youtube, 2014), muitas crianças verbalizaram que já o conhecia e demonstraram entusiasmo em aprender o modelo de coreografia apresentado, como uma criança que disse: "Vou cantar essa música com os meus irmãos em casa". 
Com base na participação e envolvimento das crianças com as atividades propostas do tema amizade, observou-se que as vivências utilizando estímulos visuais, vídeo musical, expressão corporal e roda de conversa possibilitaram atingir o objetivo proposto de modo mais eficaz, tendo em vista a adesão dos mesmos, assim como o nível de compreensão do conteúdo proposto, explicitados pelos exemplos acima.

A realização do encontro justifica-se, dessa forma, por a amizade ser considerada como campo de expressividade de emoções, sendo que a maioria das pessoas não esquece amizades feitas na infância e na adolescência, especialmente devido à sua importância para o desenvolvimento social e emocional (Del Prette \& Del Prette, 2005). Juntamente a isto, a escola, além de um local de formação acadêmica, é um complexo cenário de convivência, formado por redes sociais de participação. Na escola, diversos sistemas se mantêm em relacionamento: relação entre o grupo de iguais, relação entre adultos, e relação entre adultos e alunos (Bortolini \& Maia, 2012). Dessa forma, percebe-se a importância da promoção de habilidades sociais de amizade, considerando-se importante o exercício prático de situações cotidianas, relacionadas à experiência da criança em suas relações sociais, como prevenção de bullying, por exemplo.

$\mathrm{Na}$ intervenção com o tema civilidade, trabalhou-se a expressão de regras de relacionamento aceitas na sociedade a partir do Estatuto da Criança e do Adolescente. Ao serem indagados sobre quem conhecia o ECA, muitas crianças levantaram as mãos e deram exemplos de direitos e deveres, como brincar, estudar, respeitar os colegas. Nesse momento, notabilizam-se as subclasses seguir regras ou instruções, esperar a vez para falar, e fazer e responder perguntas.

Após a exposição inicial do que se tratava o estatuto, as crianças, ao serem indagadas se eram crianças ou adolescentes, responderam que eram crianças, o que condizia com o que foi abordado e com a sua faixa-etária, uma vez que os participantes do projeto possuíam de seis a sete anos de idade.

Com a apresentação da história "A Turma da Mônica em: O Estatuto da Criança e do Adolescente" (Sousa, 2006), uma indagação que surgiu no grupo foi referente ao trabalho como menor aprendiz. Dessa forma, as facilitadoras mencionaram o exemplo de menores-aprendizes que trabalham na escola, explicando que por possuírem idade superior a dezesseis anos, eles são autorizados a trabalharem, desde que também estudem e cumpram regras específicas estabelecidas pela lei, relacionadas às suas faixas-etárias.

No momento da atividade com as placas verdes e vermelhas, que também possibilitou o trabalho da subclasse de seguir instruções e aguardar a vez, as crianças deram as respostas esperadas através do direcionamento das placas. Nesse momento, as crianças demonstraram associar tanto o conhecimento 
prévio como o adquirido sobre 0 estatuto com as situações cotidianas representadas nas frases.

Além disso, generalizavam o conteúdo das frases para situações por elas mesmo vivenciadas, como uma criança que verbalizou: "Eu guardo os meus brinquedos com meus colegas e na escola eu ajudo a 'tia' a guardar", quando a frase discutida foi "a criança ajuda sua mãe, arrumando sua cama e seu quarto".

A habilidade social de civilidade pode ser entendida como a expressão comportamental de regras mínimas de relacionamento aceitas e/ou valorizadas em uma determinada subcultura (Del Prette \& Del Prette, 2005). Nesse sentido, a habilidade social de civilidade trabalhada envolveu tanto o trabalho das subclasses dessa habilidade como das regras instituídas pelo Estatuto da Criança e do Adolescente, de modo a contribuir, através da vivência, para a promoção da classe de habilidade social em foco.

Com a realização dos encontros, percebeu-se a necessidade de as facilitadoras atentarem para as especificidades de cada grupo e para o momento da rotina escolar no qual os mesmos ocorriam. Uma turma participou da intervenção do tema amizade logo após o lanche, o que tornou necessário alterar a ordem planejada para o encontro e iniciar pela exibição do vídeo musical e pela demonstração da coreografia, por serem atividades mais dinâmicas e manterem a atenção e o interesse das crianças. Aliado a isto, a utilização de estratégias metodológicas lúdicas foi fundamental, demonstrando mais uma vez a importância de se atuar baseado nas características do público-alvo do projeto.

Verificou-se, ainda, a inter-relação das habilidades sociais conforme apontada pela literatura (Del Prette \& Del Prette, 2005), uma vez que tanto a habilidade social de amizade como de civilidade envolvem subclasses que são semelhantes, como cumprimentar pessoas, fazer e responder perguntas, elogiar e aceitar elogios, e que se coadunam para o relacionamento interpessoal.

Discorrer sobre habilidades sociais pressupõe situações nas quais mais de uma pessoa esteja interagindo com outra. No caso de crianças, encontram-se grupos de pares onde estas possam testar e aprender novas habilidades sociais. Dessa forma, observa-se que trabalhos em grupo são indicados para o desenvolvimento de habilidades sociais (De Salvo, Löhr, \& Mazzarotto, 2005).

As intervenções realizadas no Projeto Habilidades Sociais da Criança ocorreram no contexto escolar, tanto em termos protetivos quanto preventivos, para o desenvolvimento de habilidades sociais junto ao aluno, a fim de ampliar sua competência social, almejando um bom funcionamento adaptativo no que se refere a melhorias no rendimento acadêmico, responsabilidade, autonomia e cooperação apontadas pela literatura do tema. Nesse sentido, cabe ressaltar que o referido projeto promove na escola habilidades sociais no decorrer do ano letivo, no entanto, este relato focalizou os encontros envolvendo as habilidades de amizade e civilidade que contaram com a participação da estagiária. 


\section{CONSIDERAÇÕES FINAIS}

O estágio propiciou experiência prática na área de atuação da Psicologia Escolar, sendo de fundamental importância os momentos de trocas de experiência, construção e reconstrução de conhecimento, e aprendizado mútuo com a professora-supervisora da UESPI, a supervisora de campo e os estagiários de outras escolas da cidade. Nessa perspectiva, considera-se significativa a possibilidade de imbricamento teórico-prático, viabilizada pela simultânea inserção no espaço escolar e pela discussão e reflexão crítica no espaço acadêmico acerca da atuação profissional do psicólogo no contexto em foco.

A experiência em atuar e contribuir com o Projeto Habilidades Sociais da Criança constituiu-se em fonte de aprendizagem para a estagiária e crescimento para a sua formação acadêmica e futura atuação profissional. Com a realização dos encontros, percebeu-se como relevante o desenvolvimento de habilidades sociais no contexto escolar, como prevenção de conflitos e exercício de convivência coletiva. Percebeu-se também como fundamental a utilização de estratégias metodológicas lúdicas com o intuito de atuar baseado nas características do público-alvo do projeto.

\section{REFERÊNCIAS}

Almeida, S. F. C., \& Marinho-Araújo, C. M. (2010). Intervenção institucional: possibilidades de prevenção em Psicologia Escolar. In Almeida, S. F. C., \& Marinho-Araújo, C. M., Psicologia Escolar: Construção e consolidação da identidade profissional (pp. 85-95). São Paulo, SP: Alínea.

Bandeira, M., Del Prette, A., Del Prette, Z. A. P., Freitas, L. C., \& Rocha, S. S. (2006). Habilidades sociais e variáveis sociodemográficas em estudantes do ensino fundamental. Psicologia em Estudo, 11(3), 541-549. doi: 10.1590/S1413-73722006000300010

Barbieri, M., Cassins, A. M., Conti, J., Escobar, M., J., Haro, M. E. N., Junior, E. P., ... Voloschen, F. D. (2007). Manual de psicologia escolar - educacional. Curitiba, PR: Gráfica e Editora Unificado.

Bortolini, M., \& Maia, D. S. (2012). O desenvolvimento da habilidade de assertividade e a convivência na escola: relato de experiência. Psicologia em Revista, 18(3), 373-388. doi: 10.5752/P.1678-9563.2012v18n3p373

Caballo, V. E. (2003). Manual de Avaliação e Treinamento das Habilidades Sociais. Santos, SP: Santos Editora.

De Salvo, C. G, Löhr, S. S., \& Mazzarotto, I. H. K. (2005). Promoção de Habilidades Sociais em Pré-Escolares. Revista Brasileira de Crescimento e Desenvolvimento Humano, 15(1), 46-55.

Del Prette, A., \& Del Prette, Z. A. P. (2001). Psicologia das Relações Interpessoais: Vivências para o Trabalho em Grupo. Petrópolis, RJ: Vozes. 
Del Prette, A., \& Del Prette, Z. A. P. (2005). Psicologia das Habilidades Sociais na Infância: Teoria e Prática. Petrópolis, RJ: Vozes.

Dessen, M. A., \& Polonia, A. C. (2007). A Família e a Escola como contextos de desenvolvimento humano. Paidéia, 17(36), 21-32. doi: 10.1590/S0103$863 \times 2007000100003$

Sousa, M. de (2006). A Turma da Mônica em: O Estatuto da Criança e do Adolescente. São Paulo, SP: Maurício de Sousa Produções Ltda.

Youtube. (2009, agosto 18). Cascão \& Cebolinha em amizade [Video file]. Recuperado de https://www.youtube.com/watch?v=P76rnTbsWHc

Youtube. (2014, fevereiro 27). Valeu, amigo [Video file]. Recuperado de https://www.youtube.com/watch?v=4Qx-WwwHQww

Sobre os autores

Thaisa da Silva Fonseca é graduanda em Psicologia pela Universidade Estadual do Piauí (UESPI). E-mail: thaisafonseca23@hotmail.com.

Cássia Maria Lopes Dias Medeiros é psicóloga pela Universidade Estadual do Piauí (UESPI), especialista em Psicopedagogia pelo Centro Universitário Internacional (UNINTER) e especialista em Terapias Comportamentais pela Faculdade Santo Agostinho (FSA). Atua nas áreas de Psicologia Escolar e Psicologia Social. E-mail: kcia_dias@hotmail.com.

Ana Célia Sousa Cavalcante é psicóloga pela Universidade Católica de Pernambuco (UNICAP), especialista em Saúde Mental pela Universidade Federal do Rio de Janeiro (UFRJ), mestre em Saúde Coletiva pela Universidade de Fortaleza (UNIFOR), e professora do curso de Psicologia da Universidade Estadual do Piauí (UESPI). E-mail: anaceliasousa@uol.com.br.

Recebido em: 09/12/2015 $1^{\text {a }}$ revisão em: 30/04/2016 $2^{a}$ revisão em 16/05/2016 Aceito em: 22/05/2016 